\title{
Circulating cell-free DNA in plasma of locally advanced rectal cancer patients undergoing preoperative chemoradiation: A potential diagnostic tool for therapy monitoring
}

\author{
Matthias Zitt ${ }^{\mathrm{a}, 1}$, Hannes M Müller ${ }^{\mathrm{a}, 1}$, Marina Rochel ${ }^{\mathrm{b}}$, Verena Schwendinger ${ }^{\mathrm{c}}$, Marion Zitt ${ }^{\mathrm{d}}$, \\ Georg Goebel $^{\mathrm{e}}$, Alexander DeVries ${ }^{\mathrm{f}}$, Raimund Margreiter ${ }^{\mathrm{a}, \mathrm{d}}$, Michael Oberwalder ${ }^{\mathrm{a}}$, \\ Robert Zeillinger ${ }^{\mathrm{b}}$ and Dietmar Öfner ${ }^{\mathrm{a}, *}$ \\ ${ }^{a}$ Department of General and Transplant Surgery, Innsbruck Medical University, Austria \\ ${ }^{\mathrm{b}}$ Molecular Oncology Group, Department of Obstetrics and Gynecology, Vienna Medical University, Austria \\ ${ }^{\mathrm{c}}$ Department of Radiotherapy and Radiooncology, Innsbruck Medical University, Austria \\ ${ }^{\mathrm{d}}$ Tyrolean Cancer Research Institute, Innsbruck, Austria \\ ${ }^{\mathrm{e}}$ Department of Medical Statistics, Informatics and Health Economics, Innsbruck Medical University, Austria \\ ${ }^{\mathrm{f}}$ Department of Radiooncology, Feldkirch General Hospital, Academic Teaching Hospital, Feldkirch, Austria
}

\begin{abstract}
Circulating cell-free DNA opens up an interesting field for therapy monitoring, in particular during multimodal therapy protocols. The objective of this proof of principle study was to evaluate whether the amount of circulating plasma DNA has the potential to serve as a marker for therapy monitoring during the treatment course of locally advanced rectal cancer patients. We especially focused on kinetics of circulating DNA to assess whether variances in kinetics have the potential to discriminate between therapy responders and nonresponders.

The amount of circulating DNA in plasma of rectal cancer patients undergoing preoperative chemoradiation was determined using real-time PCR before chemoradiation, after the end of chemoradiation and at the end of treatment. The study population was divided into responders (ypT0-T2 stage) and nonresponders (ypT3-T4 stage). Both groups showed comparable median plasma DNA values before and after the end of chemoradiation. At the end of treatment responders showed a further decrease in circulating DNA, whereas in nonresponders the circulating DNA manifestly increased $(\mathrm{P}=0.006)$.

This study demonstrates that circulating DNA in plasma of rectal cancer patients undergoing preoperative chemoradiation might serve as a surrogate marker to discriminate between responders and nonresponders. Therefore, we hypothesize that quantification of plasma DNA could be of use as an easily accessible tool for therapy monitoring in these patients.
\end{abstract}

Keywords: Circulating DNA, plasma, rectal cancer, preoperative chemoradiation, therapy monitoring

\footnotetext{
${ }^{1}$ These authors contributed equally to this work.

${ }^{*}$ Corresponding author: Dietmar Öfner, MD, Department of General and Transplant Surgery, Innsbruck Medical University, Anichstrasse 35, A-6020 Innsbruck, Austria. Tel.: +43 512 5040; Fax.: +43512504 28519; E-mail: dietmar.oefner@i-med.ac.at.
}

\section{Introduction}

Despite improvements in screening programs, surgical techniques and the introduction of (neo)adjuvant treatment, rectal cancer remains one of the most common malignancies and one of the leading causes of cancer death in the western world [1]. Preoperative treatment either as short-course radiation or as combined 
chemoradiation followed by surgery is the current standard of treatment for patients with locally advanced rectal cancer [2-4]. Patients responding to combined chemoradiation as seen by histopathologic downstaging are those who benefit most [5-8]. However, some rectal cancers are either inherently resistant to preoperative therapy or they develop resistance during therapy, and therefore tumor response varies with histopathologic downstaging in 30\%-60\% and complete histopathologic response in $4 \%-30 \%$ of patients $[6,9]$. Better molecular knowledge of tumor response could be the first step toward more individual and efficient treatment strategies $[10,11]$. Recently, our group clearly demonstrated that rectal cancers in therapy responders and nonresponders show different biologic behavior with regard to the occurrence or absence of disseminated tumor cells in peripheral blood [12]. Such a bloodbased diagnostic test could be an additional means of molecular differentiation of tumor response to a given treatment and one that can be combined with the histopathologic evaluation of the tumor.

The presence of circulating nucleic acids in plasma and serum (CNAPS) of cancer patients was recognized in the 1970s $[13,14]$. Meantime, it is widely accepted that a substantial proportion of circulating cell-free DNA in plasma of cancer patients originates from tumor cells $[15,16]$, but despite many experiments performed by several groups it remains unclear whether circulating tumor-associated DNA results from tumor necrosis, apoptosis or a new mechanism of active release $[17,18]$. Fleischhacker et al. reported in their comprehensive review that DNA concentration in plasma of cancer patients is higher than in healthy subjects, but they also emphasized that there is an overlap and that an increased plasma DNA level was also observed in patients with premalignant disease, inflammation, trauma and in elderly patients suffering from acute or chronic illnesses [17]. Of 54 studies dealing with DNA quantification in plasma/serum listed in that review, only four studies focused on plasma DNA quantification in colorectal cancer patients. Unfortunately, all tumor stages were included and various quantification methods were used in the studies [19-22], making it difficult to interpret the findings. In order to prevent technical or methodological misinterpretation caused by variations in DNA concentrations in circulating plasma, some experts postulate that it is more essential to analyze the kinetics of the plasma DNA concentration in patients suffering from cancer, in particular during the treatment course [17].

The easy accessibility and the chemically stability of CNAPS open an interesting field for therapy monitor- ing, in particular during multimodal therapy concepts, e.g. preoperative chemoradiation followed by surgery in patients with locally advanced rectal cancer. To our knowledge, circulating cell-free DNA in plasma of locally advanced rectal cancer patients has not been quantified in the course of preoperative chemoradiation and surgery or correlated with histopathologic response.

Therefore, the objective of this present proof of principle study was to evaluate whether the amounts of circulating plasma DNA measured by real-time PCR have the potential to serve as a diagnostic marker for therapy monitoring during the course of treatment of locally advanced rectal cancer patients. We especially focused on the kinetics of circulating plasma DNA to address whether variances in kinetics have the potential to discriminate between therapy responders and nonresponders.

\section{Materials and methods}

\subsection{Patients and treatment}

The current study population included 26 patients, namely 19 men and 7 women [aged 34-83 years (meanage, 63.1 years; standard deviation, \pm 10.9 ); the same patients were enrolled in our recently published study dealing with disseminated tumor cells [12]]. At the time of diagnosis, all study patients had histopathologically confirmed adenocarcinoma of the mid- and low rectum with locally advanced disease (in our setting: cT3 or cT4 tumors (cT is short for clinical $\underline{\mathrm{T}}$ stage according to the guidelines of the International Union Against Cancer), independent of nodal status; staged with rectal endosonography and magnetic resonance imaging) and were scheduled for preoperative chemoradiation. Patients with cT1 and cT2 tumors, distant metastases or other malignant disease in their medical history were excluded. Performed treatment [preoperative chemoradiation for a cumulative dose of $45 \mathrm{~Gy}(1.8 \mathrm{~Gy} / \mathrm{d})$ combined with $350 \mathrm{mg} 5$ Fluorouracil $/ \mathrm{m}^{2} / \mathrm{d}$ on every treatment day, followed by radical surgery] was described previously [12]. Resected tumors were histopathologically examined according to the guidelines of the Union Internationale Contre le Cancer (UICC) and tumor grading. This examination provided the yp T stage (yp is the prefix for $\mathrm{T}$ stage after preoperative chemoradiation and resection according to the guidelines of the UICC) that we were able to define responders and nonresponders by comparing cT stage and ypT stage. 
Table 1

Demographic and clinicopathologic data, status of therapy response and concentration of free circulating DNA in plasma [ng DNA/mL plasma] of each patient at each defined time of peripheral blood sample collection (T1, T2, T3).

\begin{tabular}{cccccccccccccc}
\hline ID & sex & age & surgery & cT & ypT & ypN & M & UICC & G & response & T1 & T2 & T3 \\
1 & $\mathrm{f}$ & 61.2 & LAR & 4 & 4 & 0 & 0 & 2 & 2 & non-r & 1.18 & 7.69 & 7.73 \\
2 & $\mathrm{~m}$ & 61.1 & APE & 3 & 3 & 2 & 0 & 3 & 3 & non-r & 8.83 & 0.42 & 5.08 \\
3 & $\mathrm{~m}$ & 67.5 & LAR & 3 & 3 & 1 & 1 & 4 & 2 & non-r & 0.58 & 0.99 & 10.33 \\
4 & $\mathrm{~m}$ & 60.1 & LAR & 3 & 3 & 0 & 0 & 2 & 2 & non-r & 1.00 & 0.96 & 60.92 \\
5 & $\mathrm{~m}$ & 71.6 & LAR & 3 & 3 & 1 & 0 & 3 & 2 & non-r & 1.43 & 0.12 & 3.80 \\
6 & $\mathrm{f}$ & 61.1 & APE & 3 & 3 & 2 & 0 & 3 & 2 & non-r & 0.53 & 0.93 & 5.12 \\
7 & $\mathrm{~m}$ & 82.7 & LAR & 3 & 3 & 1 & 0 & 3 & 3 & non-r & 21.59 & na & na \\
8 & $\mathrm{~m}$ & 68.0 & LAR & 3 & 3 & 0 & 0 & 2 & 2 & non-r & 33.42 & na & 1.44 \\
12 & $\mathrm{f}$ & 33.8 & LAR & 3 & 3 & 1 & 0 & 3 & 2 & non-r & 2.64 & 0.46 & 4.83 \\
13 & $\mathrm{~m}$ & 62.3 & LAR & 3 & 3 & 1 & 0 & 3 & 3 & non-r & 15.06 & 2.74 & 33.13 \\
15 & $\mathrm{f}$ & 75.1 & APE & 3 & 3 & 1 & 0 & 3 & 2 & non-r & 46.39 & 2.39 & 1.58 \\
18 & $\mathrm{~m}$ & 70.9 & APE & 3 & 3 & 1 & 0 & 3 & 2 & non-r & na & 1.28 & 5.65 \\
20 & $\mathrm{f}$ & 74.8 & LAR & 3 & 3 & 1 & 0 & 3 & 2 & non-r & 3.63 & 0.90 & 4.14 \\
21 & $\mathrm{~m}$ & 55.9 & APE & 3 & 3 & 0 & 0 & 2 & 2 & non-r & na & na & 452.30 \\
22 & $\mathrm{~m}$ & 69.3 & LAR & 4 & 4 & 2 & 1 & 4 & 2 & non-r & 5.18 & 1.75 & 3.73 \\
23 & $\mathrm{~m}$ & 62.2 & APE & 3 & 3 & 1 & 0 & 3 & 2 & non-r & 0.72 & na & 1.01 \\
24 & $\mathrm{~m}$ & 41.5 & LAR & 3 & 3 & 0 & 0 & 2 & 3 & non-r & 3.58 & na & 366.98 \\
26 & $\mathrm{~m}$ & 60.7 & LAR & 3 & 3 & 1 & 0 & 3 & 2 & non-r & 20.99 & na & 7.94 \\
9 & $\mathrm{~m}$ & 64.5 & LAR & 3 & 2 & 1 & 0 & 3 & 2 & r & 4.76 & 2.56 & 1.11 \\
10 & $\mathrm{~m}$ & 75.6 & LAR & 3 & 2 & 0 & 0 & 1 & 2 & r & na & 5.33 & 1.62 \\
11 & $\mathrm{~m}$ & 66.4 & LAR & 3 & 0 & 0 & 0 & 1 & 2 & r & 34.40 & 0.46 & 1.53 \\
14 & $\mathrm{~m}$ & 64.5 & LAR & 3 & 2 & 0 & 0 & 1 & 1 & r & 1.19 & 3.54 & 4.36 \\
16 & $\mathrm{~m}$ & 65.0 & APE & 3 & 1 & 0 & 0 & 1 & 2 & $\mathrm{r}$ & 11.92 & 1.04 & 2.71 \\
17 & $\mathrm{~m}$ & 62.8 & LAR & 3 & 1 & 0 & 0 & 1 & 2 & $\mathrm{r}$ & 9.74 & 0.36 & 1.22 \\
19 & $\mathrm{f}$ & 61.8 & APE & 3 & 2 & 0 & 0 & 1 & 2 & $\mathrm{r}$ & na & 3.20 & 3.20 \\
25 & $\mathrm{f}$ & 40.5 & LAR & 3 & 0 & 0 & 0 & 1 & 2 & $\mathrm{r}$ & 0.91 & na & 2.84 \\
\hline
\end{tabular}

$\mathrm{f}=$ female; $\mathrm{m}=$ male; $\mathrm{LAR}=$ low anterior resection; $\mathrm{APE}=$ abdominoperineal excision; $\mathrm{cT}=$ clinical $\mathrm{T}$ stage; $\mathrm{ypT}=\mathrm{T}$ stage after preoperative chemoradiation and resection; ypN = nodal stage after preoperative chemoradiation and resection; $\mathrm{M}=$ metastasis; UICC $=$ Union Internationale Contre le Cancer (UICC stage: $1=$ UICC I, $2=$ UICC II, 3 = UICC III, 4 = UICC IV); G = grading; non-r = nonresponder, $\mathrm{r}=$ responder; T1 = before initiation of chemoradiation, $\mathrm{T} 2=$ after the end of chemoradiation, $\mathrm{T} 3=$ postoperatively at the end of treatment; na $=$ not available

Patients with ypT stage 0,1 and 2 tumors - thus showing downstaging - were defined as histopathologic responders, and those patients with no change in $\mathrm{T}$ stage (ypT3 and ypT4 tumors with no downstaging) as nonresponders. Patient demographics are given in Table 1.

\subsection{Ethics}

The trial was approved by the local Institutional Review Board and was performed in accordance with the Helsinki Declaration of 1975, as revised in 1983. Written informed consent was obtained from all patients after the nature of the procedure had been fully explained to them.

\subsection{Sample collection}

Venous blood samples $(8 \mathrm{ml}$; in tubes containing EDTA) were collected from each patient at three de- fined times during the treatment course (T1-T3): before initiation of chemoradiation $=\mathrm{T} 1$, after the end (i.e. fifth week) of chemoradiation $=\mathrm{T} 2$, and postoperatively at the end of treatment $=\mathrm{T} 3$. To avoid inclusion of venipuncture-cored skin epithelial cells in the blood sample, the blood was preaspirated from the cannula.

Plasma was carefully removed by centrifugating twice at $3000 \mathrm{rpm}$ for $10 \mathrm{~min}$ at $4{ }^{\circ} \mathrm{C}(2 \mathrm{~h}$ after venipuncture) without touching the cell pellet. The resulting supernatant (plasma) was divided into aliquots (in clean polypropylene tubes) and stored at $-80^{\circ} \mathrm{C}$ until processing.

Finally, 66 of 78 anticipated plasma samples were obtained from the 26 prospectively included patients and analyzed.

\subsection{DNA preparation}

DNA was isolated from $125 \mu \mathrm{l}-240 \mu \mathrm{l}$ plasma with the QIAamp DNA Blood Mini Kit (Qiagen) according 
to the manufacturer's instructions and eluted with $40 \mu \mathrm{l}$ distilled water.

\subsection{Quantification of plasma DNA by real-time PCR}

Primers and probe for quantification of the $18 \mathrm{~S}$ gene were obtained as an Assay-on-Demand kit, (Hs99999901_s1; Applied Biosystems). A 7900HT Sequence Detection System (Applied Biosystems) was used for real-time analysis. DNA aliquots $(4 \mu \mathrm{l})$ were used as templates for PCR in a total volume of $14 \mu \mathrm{l}$ including “TaqMan Universal PCR Master Mix No Amp Erase UNG" (Applied Biosystems) and the corresponding probes and primers. The mixtures were pre-incubated at $50^{\circ} \mathrm{C}$ for $2 \mathrm{~min}$ and then at $90^{\circ} \mathrm{C}$ for $10 \mathrm{~min}$ followed by 50 cycles of two-step incubation at $95^{\circ} \mathrm{C}$ for $15 \mathrm{~s}$ and $60^{\circ} \mathrm{C}$ for $1 \mathrm{~min}$. All samples were measured in duplicate. For a standard curve placenta DNA was used at concentrations of $0.15 \mathrm{ng} / \mathrm{ml}$ to $2500 \mathrm{ng} / \mathrm{ml}$. Of the standard solutions $4 \mu \mathrm{l}$ was used in PCR as described above. DNA concentrations in the plasma samples were calculated as ng DNA/ml plasma. Quantification of plasma DNA was performed by technicians having no knowledge of the patient or of the time of blood collection during the treatment course.

\subsection{Statistical analysis}

Descriptive results are expressed as median and $25 \% / 75 \%$ percentiles. Global time-oriented comparisons of median plasma DNA concentrations within the entire study population and within the two groups (histopathologic responders and nonresponders) were performed by using the Friedmann Test, and post hoc tests were made with the Wilcoxon Test. For multiple tests Bonferroni correction was applied. Comparisons of median plasma DNA concentrations between histopathologic responders and nonresponders for each defined time (T1, T2, T3) were done with using the Mann-Whitney U Test. A P-value of $<0.05$ was considered statistically significant. All statistical analyses were performed with SPSS ${ }^{\circledR}$ for Windows v10.0 (SPSS Inc., Chicago, IL).

\section{Results}

\subsection{Clinical data}

After preoperative chemoradiation 18 patients (69\%) underwent low anterior resection (LAR), and eight patients $(31 \%)$ underwent abdominoperineal excision (APE). Two patients were staged ypT0, two patients ypT1, four patients ypT2, 16 patients ypT3 and two patients ypT4, giving eight histopathologic responders $(31 \%)$ and 18 nonresponders $(69 \%)$. None of the patients staged ypT3 or ypT4 experienced downstaging in $\mathrm{T}$ stage during preoperative chemoradiation (compare cT stage and ypT stage in Table 1).

Clinical data are given in Table 1.

\subsection{Quantitative analysis of circulating DNA}

Concentrations of cell-free DNA circulating in plasma of each patient at each defined time of blood sample collection (T1, T2, T3) are presented in Table 1. DNA levels were measurable in all plasma samples obtained and ranged from $0.12 \mathrm{ng} / \mathrm{ml}$ to $452.3 \mathrm{ng} / \mathrm{ml}$.

In the entire study population circulating DNA showed a median value of $4.2 \mathrm{ng} / \mathrm{ml}(1.1 / 16.5)$ before chemoradiation (T1), $1.0 \mathrm{ng} / \mathrm{ml}(0.5 / 2.7)$ after the end of chemoradiation (T2) and $4.1 \mathrm{ng} / \mathrm{ml}(1.6 / 7.8)$ at the end of treatment (T3) and thus statistically significant alterations throughout the treatment course (Friedmann Test: $\mathrm{P}=0.007)$.

When looking at histopathological responders and nonresponders (Fig. 1) we detected comparable plasma DNA levels before chemoradiation [T1: $7.3 \mathrm{ng} / \mathrm{ml}$ (2.1/11.4), $3.6 \mathrm{ng} / \mathrm{ml}$ (1.1/16.5), respectively; MannWhitney U Test: $\mathrm{P}=0.693$ ] and after the end of chemoradiation [T2: $2.6 \mathrm{ng} / \mathrm{ml}(0.8 / 3.4), 1.0 \mathrm{ng} / \mathrm{ml}$ $(0.8 / 1.9)$, respectively; Mann-Whitney U Test: $\mathrm{P}=$ 0.340]. However, at the end of treatment (T3) we demonstrated a statistically significant difference between responders and nonresponders (Mann-Whitney $\mathrm{U}$ Test: $\mathrm{P}=0.006)$ : responders showed a further decrease in circulating DNA $[2.2 \mathrm{ng} / \mathrm{ml}(1.5 / 2.9)]$, whereas in nonresponders the circulating DNA manifestly increased $[5.1 \mathrm{ng} / \mathrm{ml}(3.8 / 10.3)]$. In contrast to responders (Friedmann Test: $\mathrm{P}=0.165$ ), the group of nonresponders (Friedmann Test: $\mathrm{P}=0.012$ ) demonstrated statistically significant alterations throughout the treatment course. When analyzed pairwise, nonresponders showed a significant increase of plasma DNA levels from the end of chemoradiation (T2) to the end of treatment (T3; Wilcoxon Test: $\mathrm{P}=0.004)$.

The kinetics of median circulating plasma DNA levels in the responders and nonresponders are presented in Fig. 1. 


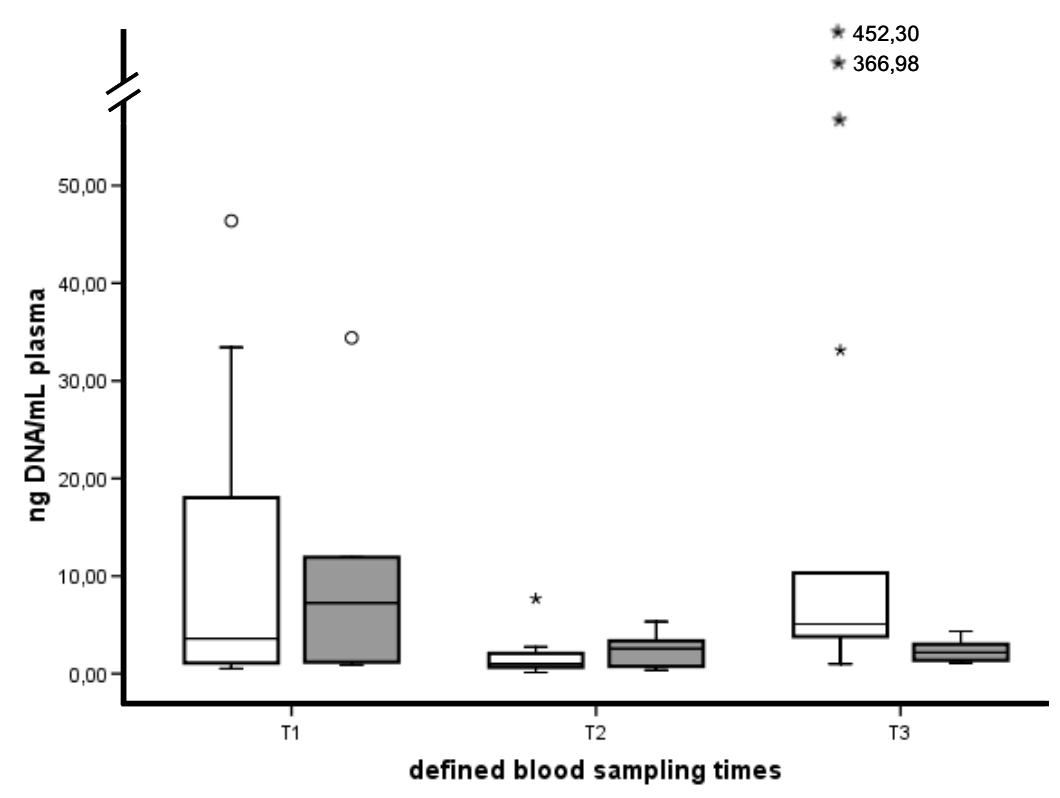

Fig. 1. Boxplots of median circulating cell-free DNA in plasma of locally advanced rectal cancer patients $(n=26)$, classified as responders ( $n=8$, grey boxplots) and nonresponders ( $n=18$, white boxplots), at defined blood sampling times during treatment (T1 $=$ before initiation of chemoradiation, $\mathrm{T} 2=$ after the end of chemoradiation, $\mathrm{T} 3=$ postoperatively at the end of treatment).

\section{Discussion}

In recent years, several studies clearly demonstrated the efficacy of preoperative chemoradiation in the treatment of locally advanced extraperitoneal rectal cancer, in particular with regard to tumor downstaging, local control, toxicity and sphincter preservation [24]. Based on these trials, preoperative chemoradiation is being increasingly performed, irrespective of the knowledge that therapy response varies with downstaging in 30\%-60\% and complete histopathologic response in 4\%-30\% of patients [6,9]. Accurate differentiation between histopathologic responders and nonresponders would have great impact on the decision to continue or modify anticancer therapy after surgery. Therefore, it seems plausible to develop molecular markers as a diagnostic tool for monitoring therapy, ideally using simple blood collection instead of more invasive procedures. Quantification of circulating cellfree DNA in plasma might be a promising instrument that can be applied as an easily accessible and rapid means of monitoring therapy to evaluate the efficacy of (neo)adjuvant chemo-/radiotherapy in cancer patients $[17,18,23]$. To our knowledge, the literature contains no report on free circulating plasma DNA correlated with therapy monitoring during the treatment of rectal cancer patients undergoing preoperative chemoradiation.
The current study detected circulating DNA in all plasma samples obtained during the treatment course using quantitative real-time PCR. At the time of diagnosis (before chemoradiation; T1), our patients, who comprise a homogeneous group of locally advanced rectal cancer patients without distant metastasis, had plasma DNA levels from $0.53 \mathrm{ng} / \mathrm{ml}$ to $46.39 \mathrm{ng} / \mathrm{ml}$ [median: $4.2 \mathrm{ng} / \mathrm{ml}(1.1 / 16.5)]$. In the literature, median plasma DNA values for colorectal cancer ranged from $10.6 \mathrm{ng} / \mathrm{ml}$ to $709 \mathrm{ng} / \mathrm{ml}$, but various tumor stages were enrolled and various quantification methods were used [19,20,22]. Several studies involving quantification of free circulating DNA in lung cancer also report noticeable variations in plasma DNA values (mean plasma DNA concentrations from 3.7-318 $\mu \mathrm{g} / \mathrm{L}$ ) [2430]. Moreover, it seems clear that there is no correlation between plasma DNA concentration and tumor size, tumor site or tumor stage [26,28,31].

Because the situation concerning free circulating DNA values in plasma of cancer patients is inconclusive, a single quantitative analysis of circulating DNA seems to be of limited value. Therefore, some experts feel that it is more essential to analyze the kinetics of the plasma DNA concentration in cancer patients, in particular during the course of treatment [17]. As outlined above, the central objective of our present study was to evaluate whether the amounts of circulating plasma DNA in patients with locally advanced 
rectal cancer have the potential to serve as a diagnostic marker for therapy monitoring during treatment. We especially focused on the kinetics of circulating plasma DNA to assess whether differences in kinetics have the potential to discriminate between therapy responders and nonresponders. For this purpose, the investigation was planned as proof of principle study, and we therefore did not correlate circulating DNA levels during treatment with clinical outcome.

Comparison of histopathological responders and nonresponders revealed comparable plasma DNA levels before and after the end of chemoradiation, but a statistically significant difference at the end of treatment. Responders showed a further decrease in circulating DNA, whereas in nonresponders the circulating DNA manifestly increased ( $\mathrm{P}=0.006$; Fig. 1). These cardinal findings are consistent with those several studies in lung cancer patients showing a correlation between the measured levels of circulating DNA and response to a given therapy. Those trials demonstrated that response is associated with a decrease in the plasma DNA level, whereas no change or even an increase in the amount of free circulating DNA was seen in patients who do not respond to therapy [13, 28,29,32]. Moreover, the findings in the present study are also consistent with those in our recently published study dealing with circulating tumor cells in the same 26 patients. That study found a statistically significant decrease in tumor cell positivity in the peripheral blood of responders from initiation of chemoradiation to the end of treatment, whereas no statistically noticeable alterations were detected in the peripheral blood of nonresponders. Thus, comparison of responders and nonresponders demonstrated that locally advanced rectal cancers subjected to preoperative chemoradiation show different biologic behavior in terms of tumor cell dissemination in peripheral blood [12]. The current study confirmed the results of our previous study by detecting a difference in the kinetics of circulating cell-free DNA in the plasma of locally advanced rectal cancer patients during treatment and showing that this difference correlates with histopathological response. The source of the circulating cell-free DNA and its definite role remain elusive [15]: Circulating tumor-specific genetic information may serve as a surrogate marker for circulating tumor cells that ultimately cause distant metastases. An alternative, but equally attractive, hypothesis is that circulating altered DNA per se may cause de novo development of tumor cells in organs known to harbor cancer metastases. This so-called "Hypothesis of Genometastasis" suggests that malignant transfor- mation might develop as a result of the transfection of susceptible cells to distant target organs with dominant oncogenes that circulate in the plasma and are derived from the primary tumor [33].

Fleischhacker et al. concluded in their review that free-circulating nucleic acids are a very interesting target for the development of clinically useful assays, since several studies showed a correlation between circulating nucleic acids and clinical data such as prognosis and therapy response [17].

With regard to locally advanced rectal cancer patients undergoing preoperative chemoradiation followed by surgery, we demonstrate that circulating cell-free plasma DNA might serve as a surrogate marker for discriminating between therapy responders and nonresponders. Therefore, we hypothesize that detection and quantification of circulating plasma DNA could be of use as an easily accessible tool for monitoring therapy in these patients during treatment. Additional studies including more patients are needed to elucidate the prognostic and predictive potential of circulating cell-free DNA in the plasma of preoperatively chemoradiated rectal cancer patients.

\section{Acknowledgments}

This study was funded in part by research grants from: Österreichische Nationalbank (ÖNB, Grant No.: 10929), Wissenschaftsfond des Landes Tirol, Österreichische Krebshilfe-Krebsgesellschaft Tirol and Chirurgisch-Onkologische Forschungsförderung (COFF).

\section{References}

[1] A. Jemal, R. Siegel, E. Ward, T. Murray, J. Xu and M.J. Thun, Cancer statistics, CA Cancer J Clin 57 (2007), 43-66.

[2] J.F. Bosset, G. Calais, L. Mineur et al., Enhanced tumorocidal effect of chemotherapy with preoperative radiotherapy for rectal cancer: preliminary results-EORTC 22921, J Clin Oncol 23 (2005), 5620-5627.

[3] J.F. Bosset, L. Collette, G. Calais et al., Chemotherapy with preoperative radiotherapy in rectal cancer, $N$ Engl J Med 355 (2006), 1114-1123.

[4] R. Sauer, H. Becker, W. Hohenberger et al., Preoperative versus postoperative chemoradiotherapy for rectal cancer, $N$ Engl J Med 351 (2004), 1731-1740.

[5] N.A. Janjan, C. Crane, B.W. Feig et al., Improved overall survival among responders to preoperative chemoradiation for locally advanced rectal cancer, Am J Clin Oncol 24 (2001), $107-112$. 
[6] G. Theodoropoulos, W.E. Wise, A. Padmanabhan et al., Tlevel downstaging and complete pathologic response after preoperative chemoradiation for advanced rectal cancer result in decreased recurrence and improved disease-free survival, Dis Colon Rectum 45 (2002), 895-903.

[7] V. Valentini, C. Coco, A. Picciocchi et al., Does downstaging predict improved outcome after preoperative chemoradiation for extraperitoneal locally advanced rectal cancer? A longterm analysis of 165 patients, Int J Radiat Oncol Biol Phys $\mathbf{5 3}$ (2002), 664-674

[8] J.M. Wheeler, E. Dodds, B.F. Warren et al., Preoperative chemoradiotherapy and total mesorectal excision surgery for locally advanced rectal cancer: correlation with rectal cancer regression grade, Dis Colon Rectum 47 (2004), 2025-2031.

[9] J. Garcia-Aguilar, A.E. Hernandez de, P. Sirivongs, S.H. Lee, R.D. Madoff and D.A. Rothenberger, A pathologic complete response to preoperative chemoradiation is associated with lower local recurrence and improved survival in rectal cancer patients treated by mesorectal excision, Dis Colon Rectum 46 (2003), 298-304

[10] B. Molnar, L. Floro, F. Sipos, B. Toth, L. Sreter and Z. Tulassay, Elevation in peripheral blood circulating tumor cell number correlates with macroscopic progression in UICC stage IV colorectal cancer patients, Dis Markers 24 (2008), 141-150.

[11] A.R. He, J. Mendelson, T. Blake, L. Mishra and J.L. Marshall, Stem cells in gastrointestinal cancers, Dis Markers 24 (2008), 217-222.

[12] M. Zitt, M. Zitt, H.M. Muller et al., Disseminated tumor cells in peripheral blood: a novel marker for therapy response in locally advanced rectal cancer patients undergoing preoperative chemoradiation, Dis Colon Rectum 49 (2006), 1484-1491.

[13] S.A. Leon, B. Shapiro, D.M. Sklaroff and M.J. Yaros, Free DNA in the serum of cancer patients and the effect of therapy, Cancer Res 37 (1977), 646-650.

[14] B. Shapiro, M. Chakrabarty, E.M. Cohn and S.A. Leon, Determination of circulating DNA levels in patients with benign or malignant gastrointestinal disease, Cancer 51 (1983), 21162120 .

[15] P. Anker, H. Mulcahy, X.Q. Chen and M. Stroun, Detection of circulating tumour DNA in the blood (plasma/serum) of cancer patients, Cancer Metastasis Rev 18 (1999), 65-73.

[16] M. Stroun, P. Anker, P. Maurice, J. Lyautey, C. Lederrey and M. Beljanski, Neoplastic characteristics of the DNA found in the plasma of cancer patients, Oncology 46 (1989), 318-322.

[17] M. Fleischhacker and B. Schmidt, Circulating nucleic acids (CNAs) and cancer-a survey, Biochim Biophys Acta 1775 (2007), 181-232.

[18] G. Goebel, M. Zitt, M. Zitt and H.M. Muller, Circulating nucleic acids in plasma or serum (CNAPS) as prognostic and predictive markers in patients with solid neoplasias, Dis Markers 21 (2005), 105-120.

[19] F. Diehl, M. Li, D. Dressman et al., Detection and quantifi- cation of mutations in the plasma of patients with colorectal tumors, Proc Natl Acad Sci USA 102 (2005), 16368-16373.

[20] T. Lecomte, A. Berger, F. Zinzindohoue et al., Detection of free-circulating tumor-associated DNA in plasma of colorectal cancer patients and its association with prognosis, Int J Cancer 100 (2002), 542-548.

[21] C. Stemmer, M. Beau-Faller, E. Pencreac'h et al., Use of magnetic beads for plasma cell-free DNA extraction: toward automation of plasma DNA analysis for molecular diagnostics, Clin Chem 49 (2003), 1953-1955.

[22] M.A. Thijssen, D.W. Swinkels, T.J. Ruers and J.B. de Kok, Difference between free circulating plasma and serum DNA in patients with colorectal liver metastases, Anticancer Res 22 (2002), 421-425.

[23] A.K. Pathak, M. Bhutani, S. Kumar, A. Mohan and R. Guleria, Circulating cell-free DNA in plasma/serum of lung cancer patients as a potential screening and prognostic tool, Clin Chem 52 (2006), 1833-1842.

[24] C.G. Azzoli, S. Park, J. Gomez, L. Krug, V. Miller and N. Rizvi, Measurements of total DNA and methylated tumor suppressor genes in the plasma of patients with metastatic nonsmall cell lung cancer (NSCLC) before, and after chemotherapy, as potential biomarkers for response to treatment, J Clin Oncol 23 (2005), 7203 (Abstract).

[25] M. Beau-Faller, M.P. Gaub, A. Schneider et al., Plasma DNA microsatellite panel as sensitive and tumor-specific marker in lung cancer patients, Int J Cancer 105 (2003), 361-370.

[26] O. Gautschi, C. Bigosch, B. Huegli et al., Circulating deoxyribonucleic Acid as prognostic marker in non-small-cell lung cancer patients undergoing chemotherapy, J Clin Oncol 22 (2004), 4157-4164.

[27] L.J. Herrera, S. Raja, W.E. Gooding et al., Quantitative analysis of circulating plasma DNA as a tumor marker in thoracic malignancies, Clin Chem 51 (2005), 113-118.

[28] G. Sozzi, D. Conte, L. Mariani et al., Analysis of circulating tumor DNA in plasma at diagnosis and during follow-up of lung cancer patients, Cancer Res 61 (2001), 4675-4678.

[29] G. Sozzi, D. Conte, M. Leon et al., Quantification of free circulating DNA as a diagnostic marker in lung cancer, J Clin Oncol 21 (2003), 3902-3908.

[30] G.S. Xie, A.R. Hou, L.Y. Li, Y.N. Gao and S.J. Cheng, Quantification of plasma DNA as a screening tool for lung cancer, Chin Med J (Engl) 117 (2004), 1485-1488.

[31] K. Jung, C. Stephan, M. Lewandowski et al., Increased cellfree DNA in plasma of patients with metastatic spread in prostate cancer, Cancer Lett 205 (2004), 173-180.

[32] A. Maebo, [Plasma DNA level as a tumor marker in primary lung cancer], Nihon Kyobu Shikkan Gakkai Zasshi 28 (1990), 1085-1091.

[33] D. Garcia-Olmo, D.C. Garcia-Olmo, Functionality of circulating DNA: the hypothesis of genometastasis, Ann N Y Acad Sci 945 (2001), 265-275. 


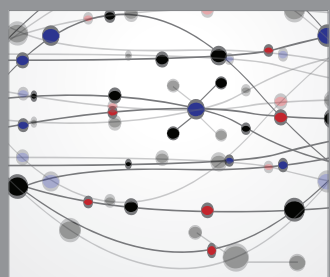

The Scientific World Journal
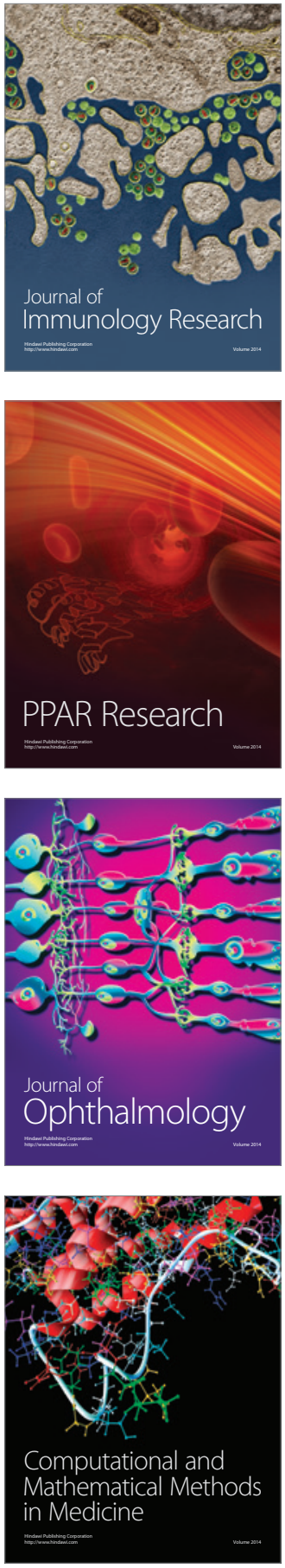

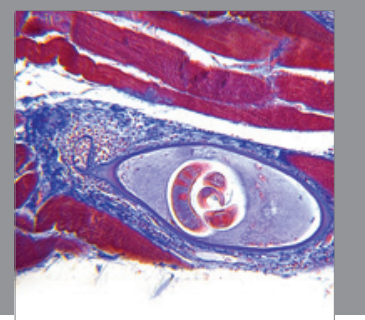

Gastroenterology

Research and Practice
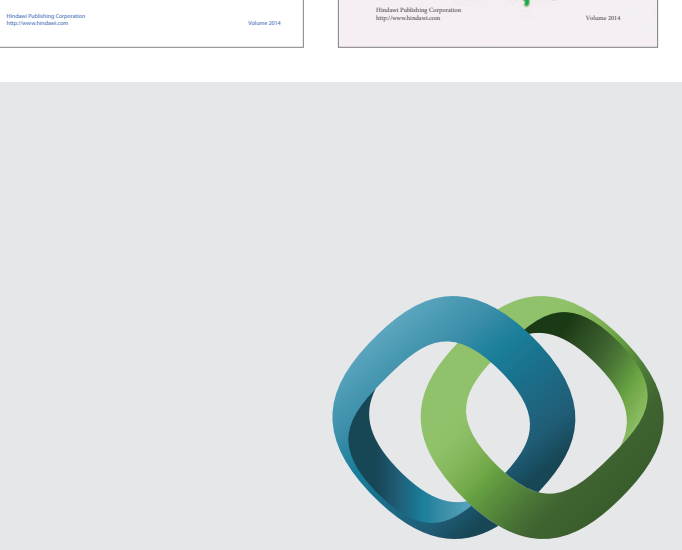

\section{Hindawi}

Submit your manuscripts at

http://www.hindawi.com
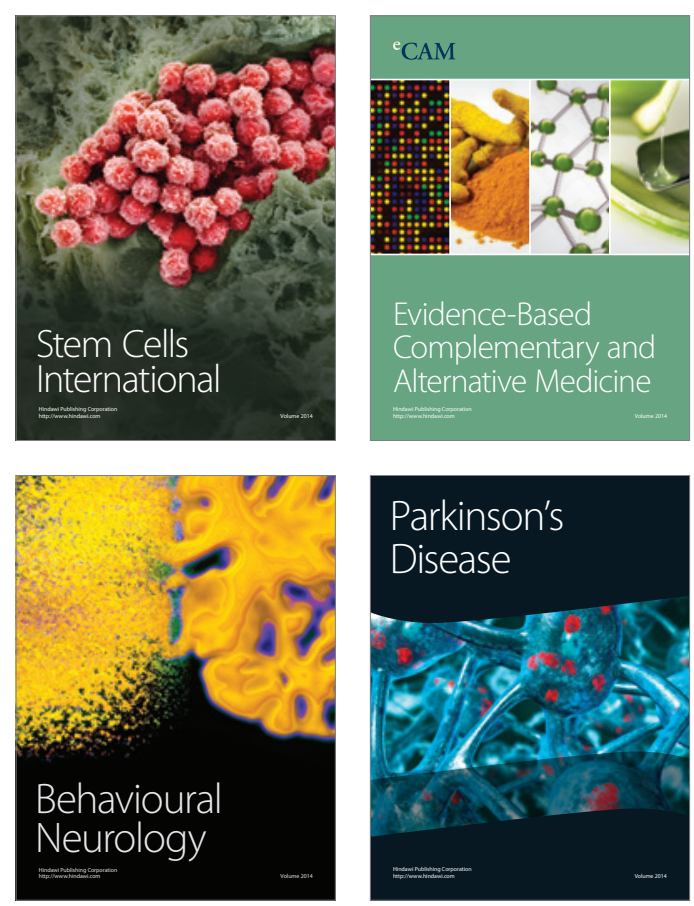

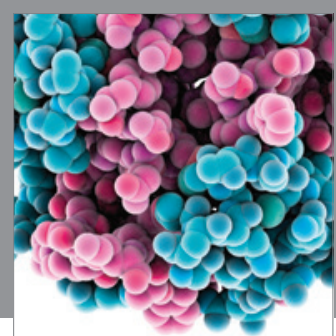

Journal of
Diabetes Research

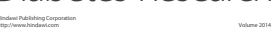

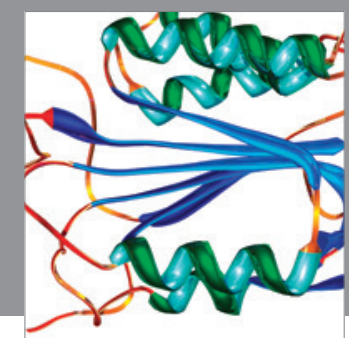

Disease Markers
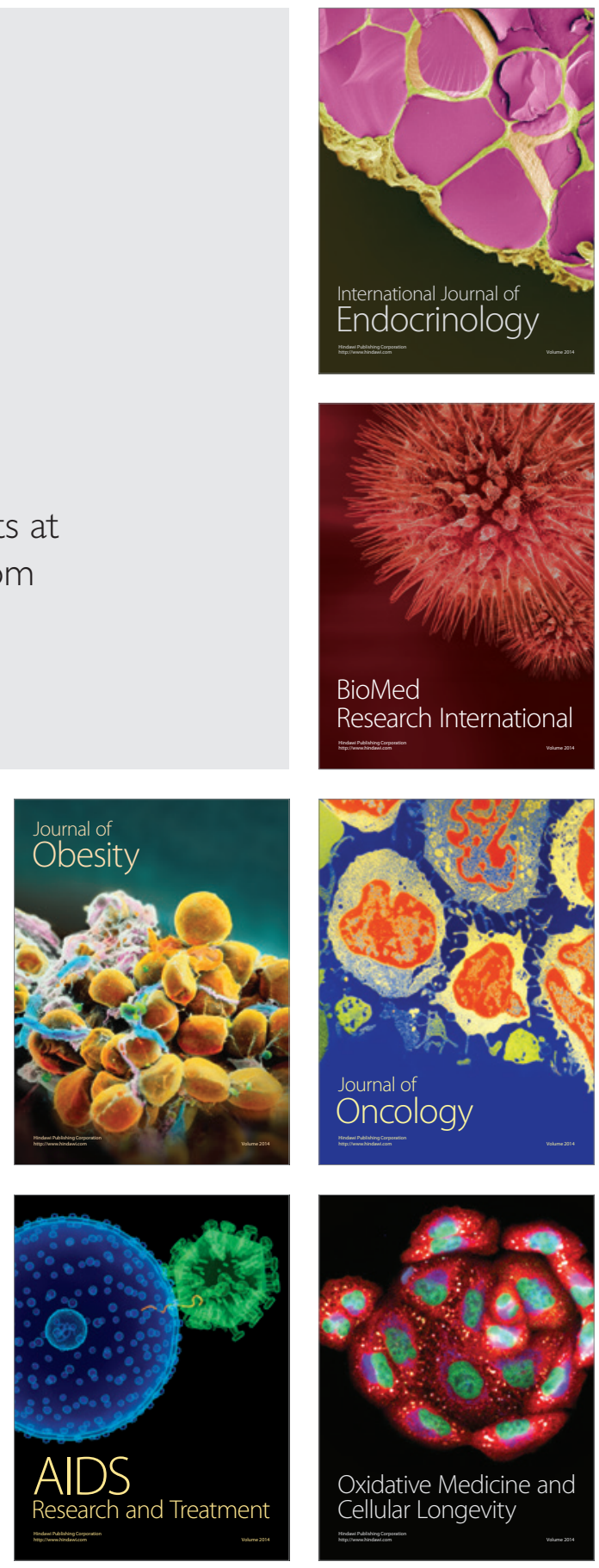